\title{
Metodologia de aValiação qualitativa das ações dos COMITÊS DE BACIAS COM ÊNFASE NA GESTÃo INTEGRADA: 0 Comitê do Alto Tietê em São Paulo
}

\author{
Methodology of qualitative evaluation of the actions of the River \\ BASINS COMMITTEES GIVING EMPHASIS TO THE INTEGRATED MANAGEMENT: \\ the High Tiete River Basin Committee in São Paulo
}

\begin{abstract}
ANGÉLICA A. TANUS BENATTI ALVIM
Arquiteta e urbanista, mestre e doutora pela Faculdade de Arquitetura e Urbanismo da Universidade de São Paulo (FAU / USP) e professora assistente da Faculdade de Arquitetura e Urbanismo - Universidade Presbiteriana Mackenzie (FAU/UPM)

\section{José LUIZ CARUSO RoNCA}

Arquiteto e urbanista, mestre, doutor, livre docente e professor titular da Faculdade de Arquitetura e Urbanismo - Universidade de São Paulo (FAU/ USP)
\end{abstract}

Código ABES: 140/06 Recebido: 24/10/06 Aceito: 04/07/07

\section{RESUMO}

Este artigo apresenta uma metodologia de avaliação qualitativa das açôes do comitê de bacia hidrográfica com ênfase na teoria de gestão integrada. Apresenta-se a teoria de gestão integrada de bacia hidrográfica e sua relação com a Política Estadual de Recursos Hídricos do Estado de São Paulo. A metodologia é construída a partir de um conjunto de indicadores qualitativos implícitos ao conceito "articulação" que mensuram de forma particularizada cada aspecto desse fenômeno. Aplica-se a metodologia nas açôes do Comitê do Alto Tietê, instância de gestão das águas da Região Metropolitana de São Paulo. Os resultados permitem verificar não só o nível de articulação de suas açôes, mas também em que aspectos esse fórum tem contribuído à gestão integrada do território metropolitano.

PALAVRAS-CHAVE: Gestão integrada, avaliação qualitativa; comitês de bacias hidrográficas

\begin{abstract}
This paper presents a method of qualitative evaluation of the actions of the river basin committee, giving emphasis to the theory of integrated management. It presents the theory of integrated management of river basins and its relation with the Politics of the State of São Paulo on water resources. The methodology is arranged from one ensemble of qualitative indicators implicit in the concept of articulation that measure in a particularized way each aspect of the phenomenon. The methodology is implemented by the study of the High Tietê River Committee, entity that is responsible for the management of water resources in the São Paulo Metropolitan Region. The results allow verifying not only the level of articulation of its actions, but also in what aspects this forum has contributed to the integrated management of the metropolitan region.
\end{abstract}

KEYWORDS: Integrated management, qualitative evaluation; River basin committee.

\section{INTRODUÇÃO Essa região considerada a área mais}

O objetivo central deste artigo é apresentar uma metodologia de avaliação qualitativa que busca mensurar a contribuição do organismo de gestão das águas, o Comitê de Bacia Hidrográfica, à gestão integrada de uma bacia hidrográfica. Destaca-se que esta metodologia foi construída no âmbito de uma pesquisa de doutoramento, defendida na FAU / USP em 2003, que escolheu como estudo de caso o Comitê de Bacia Hidrográfica do Alto Tietê, organismo que atua na Região Metropolitana de São Paulo (RMSP). populosa do Brasil (cerca de 18 milhões de habitantes em 2000), intensamente urbanizada e industrializada, apresenta sérios conflitos que interferem diretamente nos recursos hídricos os quais são, em sua maioria, provenientes do processo de ocupação desordenado do território e da ausência de planejamento urbano e metropolitano.

Desde meados dos anos de 1990, o Comitê de Bacia do Alto Tietê e seus subcomitês de bacia (Cotia - Guarapiranga; Billings - Tamanduateí; Pinheiros - Pirapora; Tietê - Cabeceiras e Juquerí - Cantareira) vêm construindo um amplo processo de planejamento participativo em relação aos conflitos que envolvem os recursos hídricos.

A avaliação das ações do Comitê do Alto Tietê e de seus sub-comitês, no período de 1996 a 2002, recorte temporal estabelecido pela pesquisa, se faz através da análise dos projetos indicados pelo Comitê e seus sub-comitês a receberem recursos do Fundo Estadual dos Recursos Hídricos - FEHIDRO com ênfase naqueles que contribuem a uma gestão integrada do território.

Esse artigo subdivide-se em cinco seções, sumarizadas a seguir. Na primeira seção, discute-se a relação da teoria de 
gestão integrada da bacia hidrográfica com a Política Estadual de Recursos Hídricos do Estado de São Paulo, e em seguida, são destacados os principais setores que apresentam interfaces com os recursos hídricos, agrupando-os, de acordo com o nível de integração entre eles e de inter-relação no território que compreende a bacia. Na segunda seção, relata-se o procedimento metodológico adotado na avaliação das ações do Comitê da Bacia. Em seguida, na terceira seção, apresenta-se uma síntese das características do estudo de caso escolhido, o Comitê do Alto Tietê, bem como a avaliação de suas ações de acordo a metodologia elaborada. A discussão dos resultados encontra-se na quarta seção onde se destacam as principais açôes que contribuíram à gestão integrada daquela bacia. As conclusōes da pesquisa, na seção 5, apontam os principais aspectos verificados na aplicação da metodologia, bem como os limites e os desafios para uma efetiva contribuição do Comitê de Bacia à gestão integrada da Bacia do Alto Tietê.

\section{A GESTÃO INTEGRADA DE BACIA HIDROGRAFICA E A POLÍTICA DE AGUAS PAULISTA}

A Constituição Federal de 1988 em seu artigo 21 definiu os princípios que fundamentam a gestão nacional de recursos hídricos e estabeleceu que a água é um bem público, considerando a necessidade de uma política integrada entre os corpos d' água e as terras que o circundam.

O Estado de São Paulo precedeu a União ${ }^{1}$ uma vez que a Constituição Paulista de 1989, além de aprofundar os princípios da Carta Magna, estabeleceu anteriormente as normas de orientação à Política Estadual de Recursos Hídricos, bem como a organização e implementação do Sistema Estadual de Gerenciamento dos Recursos Hídricos - SIGRH, regulamentados por meio da Lei $7.633 / 91$.

O SIGRH, responsável por executar a política das águas paulistas, está ancorado em três instâncias: deliberativa, por meio do Conselho Estadual de Recursos Hídricos (CRH) e dos Comitês das Bacias Hidrográficas
(CBHs), técnica, por meio do Comitê Coordenador do Plano Estadual de Recursos Hídricos (CORHI), e financeira, por meio do Fundo Estadual de Recursos Hídricos (FEHIDRO), que provém de onze fontes, dentre a compensação financeira que o Estado recebe em decorrência dos aproveitamentos hidroenergéticos em seu território e a cobrança pela utilização de recursos hídricos (que na ocasião não havia ainda sido aprovada).

A implantação dos Comitês de Bacia no Estado de São Paulo ocorreu a partir de 1993, com composição tripartite - Estado, municípios e sociedade civil - e paritária, no âmbito de cada uma das 22 Unidades de Gerenciamento dos Recursos Hídricos - UGRHIs -, regiōes definidas tendo como divisor as águas das respectivas bacias hidrográficas. Além disso, a partir de 1995 , iniciou-se a distribuição dos recursos financeiros, advindos do FEHIDRO, conforme critérios definidos no âmbito de cada Comitê, entre todos os usuários da água que participam do processo. Tais fatos possibilitaram à gestão dos recursos hídricos incorporar um formato descentralizado e democrático, e passar, em alguns casos, a encaminhar a resolução dos problemas que não necessariamente eram de sua alçada, em especial os conflitos que interferem na disponibilidade de água na bacia.

Ou seja, embora a legislação paulista tenha como principal objetivo o gerenciamento integrado dos recursos hídricos, seus fundamentos indicam os princípios do modelo de gestão integrada das bacias hidrográficas, que vai além da necessidade primaz de integração somente dos setores que envolvem os usos múltiplos da água.

Para Dourojeanny (1993) a gestão integrada da bacia hidrográfica visa conciliar políticas setoriais de gerenciamento dos recursos hídricos às políticas setoriais de gestão do território, além de integrar eqüitativamente os usuários em relação ao planejamento dos recursos hídricos. Sendo assim, defende-se nesse trabalho que para os comitês de bacia implementarem de fato a gestão integrada, estes devem buscar a articulação entre o gerenciamento integrado dos recursos hídricos e outros usos setoriais que atuam e conflitam na bacia hidrográfica em prol da sustentabilidade daquela unidade de planejamento e gestão, em suas cinco dimensões, conforme Sachs (1993): social, econômica, ambiental, espacial e cultural.

No modelo de gestão integrada de bacias hidrográficas que tem como um dos principais fundamentos os usos dos recursos ambientais, em especial os hídricos, de forma sustentável no território, o debate sobre a escassez da água, levando em conta sua capacidade de renovação e disponibilidade, é considerado sob dois prismas distintos, conforme Fracalanza (2002): o primeiro refere-se à quantidade da água necessária à execução de diferentes atividades humanas e o segundo, à qualidade da água a ser utilizada nessas mesmas atividades.

Para essa autora, a escassez da água surge das diferentes formas de apropriação deste recurso que só podem ser explicitadas quando se considera a água territorializada. Nesse sentido, a bacia hidrográfica, conjunto de terras drenadas por um rio principal, seus afluentes e subafluentes, é a unidade territorial mais indicada para um modelo de gestão que busca a conciliação de metas de sustentabilidade em todas as suas dimensōes. Assim, definir regiōes, tomando a bacia hidrográfica como unidade espacial, implica em modificar o olhar sobre o território, buscando conciliar os elementos ambientais, econômicos e sociais, em longo prazo.

Segundo Alvim (2003), os três princípios básicos da Política Estadual de Recursos Hídricos no Estado de São Paulo - Descentralização, Participação e Integração — indicados na Constituição Paulista de 1989 e explícitos na Lei Estadual 7.633/91, enfatizam aspectos contidos no modelo de gestão integrada de bacias hidrográficas. A descentralização adota a bacia hidrográfica como unidade de planejamento e gestão, possibilitando assim, a atuação descentralizada no âmbito do comitê de bacia desta unidade. A participação se expressa a partir da identificação dos atores envolvidos nos conflitos relacionados aos recursos hídricos, fato propiciado por meio da representatividade dos três segmentos usuários da água nos fóruns estadual e regional (Conselho Estadual - CRH e comitês das bacias). A integração tem em vista a não dissociação da qualidade e quantidade da água, com-

\footnotetext{
${ }^{1}$ A Constituição Federal de 1988 autoriza os Estados legislar sobre a matéria em seus respectivos territórios, resultando em proposições inovadoras, principalmente no Estado de São Paulo. A Constituição do Estado de São Paulo de 1989 veio reforçar a necessidade da gestão integrada de recursos hídricos no Estado, por meio dos seus artigos 205 a 213.
} 
pleta o argumento, uma vez que é por meio da mensuração da disponibilidade da água que as interferências das ações no território da bacia hidrográfica são evidentes.

Além destes princípios, outros aspectos da legislação, considerados fundamentais, evidenciam o propósito de uma gestão integrada de bacias, que, de acordo com Silva (2002), destacamse: incentivos à formação de consórcios intermunicipais, à formalização de convênios de mútua cooperação e assistência entre municípios e à cooperação técnica entre diversas entidades, instituições e universidades.

Nessa linha de argumentação, destaca-se que os comitês das bacias têm um papel fundamental na gestão e no planejamento dos recursos hídricos e, conseqüentemente, do território que integra a bacia, embora não seja a única instância nesse sentido. Suas açōes devem contribuir às integraçōes intersetoriais e inter-institucionais que se encontram no âmbito de outras esferas de planejamento e gestão, buscando minimizar os conflitos nos recursos hídricos, de acordo com as características do território a ser gerido.

Nesse sentido, a gestão dos recursos hídricos, como toda a política de natureza pública, apresenta interfaces de interesses, não apenas com as políticas vinculadas diretamente a esse setor ou ao meio ambiente, mas também com outras políticas setoriais, em especial as de âmbito territorial, uma vez que, em última instância, é a sustentabilidade da bacia hidrográfica que se procura alcançar.

A classificação apresentada a seguir tem o propósito de agrupar os principais setores, segundo suas respectivas características e suas distintas interfaces com os recursos hídricos, de modo a definir os graus de articulação que devem ser feitos no âmbito de cada política setorial tendo em vista o alcance efetivo da gestão integrada da bacia hidrográfica. Esses setores foram organizados em três grupos denominados de setores diretos, setores correlacionados e setores indiretos / territoriais e descritos a seguir:

- Setores Diretos: aqueles que necessariamente têm uma articulação direta e inerente com recursos hídricos, na concepção contemporânea do setor, pois se vinculam diretamente ao recurso água. Entre eles estão: o saneamento básico (água, esgoto, drenagem urbana, limpeza urbana), o setor energético e a agricultura.

- Setores Correlacionados: são setores cuja articulação é evidente na medida em que se tem o conceito de desenvolvimento sustentável ${ }^{2}$ como elemento fundamental da gestão integrada da bacia. Isso pressupõe a adoção de um conjunto de políticas que interferem e ou atuam no meio ambiente de forma integrada, embora venham sendo tratadas, na maioria das vezes, setorialmente. Nesse grupo, classificam-se: o meio ambiente, os resíduos sólidos, a educação e a saúde.

- Setores Indiretos/Territoriais: são setores de natureza territorial que demandam e interferem nos recursos hídricos e que devem ser geridos em consonância com esses de modo a atingir a gestão integrada da bacia. Nessa categoria, estão os setores-chave das políticas de ordenamento territorial urbano: uso e ocupação do solo (legislações e instrumentos); habitação; indústrias, grandes equipamentos, circulação e sistema de transportes.

Os aspectos acima ressaltados revelam as amplas interfaces existentes entre recursos hídricos e as demais instâncias e setores funcionais de uma dada região, cuja amplitude é a bacia hidrográfica, os quais devem ser geridos de forma articulada pelo Comitê de Bacia e pelas outras instâncias que atuam nesse território, em prol de um possível desenvolvimento sustentável.

\section{METODOLOGIA PROPOSTA}

Nesta pesquisa, procurou-se avaliar se as açôes de um comitê de gestão das águas contribuem à gestão integrada da bacia hidrográfica, tendo em vista a argumentação teórica apresentada na seção anterior.

A aferição das ações do Comitê do Alto Tietê foi definida por meio de princípios implícitos ao conceito articulação - conceito esse fundamental para o alcance da gestão integrada de bacias hidrográficas no âmbito de um comitê gestor das águas. São eles:

- Articulação quanto às Interfaces Setoriais: as açôes do Comitê devem expressar-se de forma articulada junto aos demais setores funcionais da bacia, em especial, setores de natureza territorial que interferem na disponibilidade de água para o abastecimento público, importante finalidade do gerenciamento de recursos hídricos.

- Articulação quanto à Abrangência Territorial: a ação do Comitê deve concentrar-se em questões de âmbito macro, privilegiando articulações entre a escala regional e sub-regional no âmbito da bacia.

- Conformidade aos objetivos de gestão: as açôes do Comitê devem ser conduzidas de modo a contribuir aos objetivos de gestão dos recursos hídricos definidos por meio de suas atribuiçōes, garantindo o atendimento aos princípios de gestão integrada dos recursos hídricos, explicitados na Lei Estadual 7.633/91.

- Coerência entre a natureza das açóes e segmento de demanda: como responsável pela gestão regional e intermunicipal, o segmento Estado tem um papel fundamental nas ações que favoreçam a gestão da bacia hidrográfica de modo integrado. A escala de gestão deve garantir que o Estado se dedique em especial às ações de amplitude regional, beneficiando tanto o segmento municipal quanto o segmento da sociedade civil.

- Justeza na alocação de recursos financeiros: espera-se que o Comitê concentre seus recursos na resolução de problemas significativos para a bacia. Nesse sentido, devem ser privilegiados tanto os projetos elencados nos instrumentos do SIGRH, como os que contribuem para a resolução de conflitos que interferem nos recursos hídricos.

Partindo do entendimento que o gerenciamento de recursos hídricos além de buscar a integração dos setores diretamente vinculados a ele, deve também buscar a articulação com os outros setores que atuam e conflitam no território da bacia ou sub-bacias, para efetivamente contribuir à gestão integrada da bacia hidrográfica, concebeu-se um conjunto de indicadores

\footnotetext{
${ }^{2}$ A definição mais conhecida de desenvolvimento sustentável é a do Relatório Nosso Futuro Comum da Comissão Mundial de Meio Ambiente, em 1987, onde "desenvolvimento sustentável é aquele que satisfaz a necessidades do presente sem comprometer as necessidades das geraçôes futuras satisfazerem as suas” (CMMAD, 1988, p.46, apud Alvim, 2003, p. 22). Diversos autores vêm aprofundando esse conceito. Dourojeanny $(1993$, p. 2) enfatiza a necessidade articulação de três objetivos que estão implícitos a ele: crescimento econômico, sustentabilidade ambiental e equidade (social, econômica e ambiental). Muñoz (2000) indica que toda a proposta que leve em consideração o desenvolvimento sustentável deve ter uma visão atualizada sobre a relação desenvolvimento e meio ambiente, sendo que a busca do crescimento econômico não deve perder de vista a preservação, a conservação e a capacidade de suporte do meio físico, base para a transformação produtiva e reserva para as futuras geraçôes.
} 
qualitativos relacionados a cada princípio implícito no conceito "articulação" descrito. Como um segundo passo, a fim de refletir o mesmo peso para os indicadores analisados, de forma a mensurar cada indicador e quantificar a avaliação de caráter qualitativo, as escalas foram transformadas em números e normalizadas em valores entre 0 e 6 , que é compatível com a representação inteira dos intervalos entre níveis. Ressalta-se que o número diferente de intervalos para graduação de indicadores surgiu da necessidade de se obter uma quantidade significativa de observaçóes para cada nível, refletindo uma uniformidade de distribuição de notas das escalas determinadas. Os indicadores construídos e suas respectivas escalas são:

- Intersetorialidade: identifica a articulação entre a gestão dos recursos hídricos e os demais setores que atuam na bacia hidrográfica, os quais estão implícitos nos projetos aprovados de acordo com suas características e o impacto de sua implementação. Para este indicador foi estabelecido uma escala (Tabela 1) de quatro níveis de articulação - alto, médio-alto, médio-baixo e baixo - definida segundo as distintas interfaces com grupos elencados na seção anterior. Por um lado, privilegiase com pontuação mais alta as açóes do Comitê que envolvem uma ampla articulação entre os setores do três grupos - "diretos"; "correlacionados" e "indiretos/territoriais" e, por outro lado, recebe uma baixa pontuação as ações voltadas apenas para o setor recursos hídricos, articulação essa implícita ao gerenciamento integrado deste setor e de responsabilidade do Comitê de Bacia.

- Abrangência territorial: esse indicador identifica a amplitude da ação do Comitê da Bacia e ou subcomitês em relação à articulação interinstitucional e territorial no âmbito da bacia (regional, sub-regional, municipal ou local), a partir do alcance dos projetos aprovados e dos segmentos envolvidos. A escala foi definida por meio de três níveis distintos - alto, médio e baixo - reforçando, por um lado, com pontuação mais alta as ações de alcance metropolitano e ou sub-regional e, por outro, com pontuação mais baixa as ações pontuais (Tabela 2). Ou seja, quanto mais a ação contribuir à bacia (entendida como região) ou as sub-bacias (sub-regiōes), mais articulada está a gestão dos recursos hídricos e, portanto, mais contribui à gestão integrada da bacia. Observa-se que as ações que se repercutem na bacia ou nas sub-bacias (correspondentes aos subcomitês de bacia) foram consideradas no mesmo nível, uma vez que no estudo de caso, a gestão descentralizada é considerada fundamental devido a complexidade da RMSP.

- Gestão: indica se o Comitê da Bacia e seus subcomitês vêm aprovando projetos que vão ao encontro dos objetivos de gestão definidos em suas atribuições (expressas claramente dos documentos formais destas instâncias). As escalas - alta, média e baixa - para esse indicador, expressas na tabela 3 , definem o nível de articulação dos projetos aprovados pelo Comitê da Bacia ou pelos sub-comitês em relação às suas atribuiçóes: quanto mais o projeto aprovado for ao encontro dos objetivos de gestão indicados nos documentos formais, mais articulado está o projeto e, portanto, sua contribuiçãao é mais significativa à gestão integrada $\mathrm{da} \mathrm{Ba}-$ cia do Alto Tietê, obtendo pontuação mais alta. Por outro lado, os projetos aprovados que não eram prioridades

Tabela I - Escalas de avaliação conforme os níveis do indicador Intersetorialidade

\begin{tabular}{|c|c|c|c|}
\hline Níveis da intersetorialidade & Critérios & \multicolumn{2}{|c|}{$\begin{array}{l}\text { Escala de } \\
\text { avaliação }\end{array}$} \\
\hline $\begin{array}{c}\text { Articulação entre os três Grupos: Direto, } \\
\text { Correlacionado e Indireto - } \\
\text { Privilégio ao Indireto/Territorial }\end{array}$ & $\begin{array}{c}\text { Projetos que prevêem articulação entre } \\
\text { os três grupos - direto, correlacionado e } \\
\text { indireto, porém a ênfase das interfaces se } \\
\text { dão com as políticas territoriais. }\end{array}$ & Alto & 6 \\
\hline $\begin{array}{l}\text { Articulação entre os três grupos: Direto, } \\
\text { Correlacionado e Indireto } \\
\text { - Privilégio aos Grupos Correlacionado e } \\
\text { Direto }\end{array}$ & $\begin{array}{c}\text { Projetos que prevêem articulação } \\
\text { entre os grupos de setores - direto, } \\
\text { correlacionado e indireto - com ênfase } \\
\text { na interface entre os dois primeiros. }\end{array}$ & $\begin{array}{l}\text { Médio } \\
\text { Alto }\end{array}$ & 4 \\
\hline $\begin{array}{c}\text { Articulação entre dois grupos: Direto } \\
\text { e Correlacionado }\end{array}$ & $\begin{array}{l}\text { Projetos que privilegiam as articulações } \\
\text { entre os setores do grupo direto } \\
\text { e correlacionado - ênfase ao setor } \\
\text { correlacionado. }\end{array}$ & $\begin{array}{l}\text { Médio } \\
\text { Baixo }\end{array}$ & 2 \\
\hline Articulação entre setores do grupo Direto & $\begin{array}{l}\text { Projetos que privilegiam somente o setor } \\
\text { de recursos hídricos - ou uma mínima } \\
\text { articulação com os setores do grupo } \\
\text { correlacionado. }\end{array}$ & Baixo & 0 \\
\hline
\end{tabular}

Tabela 2 - Escalas de avaliação conforme os níveis do indicador Abrangência Territorial

\begin{tabular}{cccc}
\hline Níveis & Critérios & \multicolumn{2}{c}{ Escala de avaliação } \\
\hline Regional/Sub-regional & Benefício extensivo a toda bacia ou sub-bacia & Alto & 6 \\
Municipal & Benefício extensivo a apenas um município & Médio & 3 \\
Bairro/local & Benefício extensivo ao bairro ou parte dele & Baixo & 0 \\
\hline
\end{tabular}


expressas pelas instâncias de gestão das águas obtiveram pontuação baixa.

- Origem do projeto: identifica a origem das demandas de projetos a serem financiados pelo Comitê da Bacia, sendo mensurado a partir de três níveis distintos de avaliação, apresentados na Tabela 4: alto, médio e baixo. Assumese que tanto o Estado como Consórcios Intermunicipais, cuja área de atuação é regional, têm maior responsabilidade nos projetos que contribuem à ges- tão integrada da bacia e, portanto, se mostram mais articulados recebendo a mais alta pontuação. As instâncias que atuam de forma localizada contribuem de maneira menos efetiva e, portanto, recebem a pontuação menor.

- Valores Contratados: indicador que classifica os projetos em relação aos valores contratados. Quanto maior o volume de recursos, maior o alcance do projeto, maior a intensidade de articulação. Como o montante recebido, anualmente pelo Comitê da Bacia ainda é pequeno (em função da não aprovação da cobrança da água), adotaram-se quatro faixas de valores, de forma que houvesse uma distribuição uniforme de projetos (Tabela 5): alto, médio-alto; médio - baixo e baixo.

Como corolário da estratégia adotada, Pereira (1999) sugere que se busque uma síntese para as várias medidas providas pelos indicadores selecionados, por meio da mensuração de um único

Tabela 3 - Escalas de avaliação conforme os níveis do indicador Gestão

\begin{tabular}{|c|c|c|c|}
\hline Níveis da Gestão & Critérios & \multicolumn{2}{|c|}{ Escala de avaliação } \\
\hline $\begin{array}{c}\text { Gestão Regional/Gestão } \\
\text { sub regional }\end{array}$ & $\begin{array}{c}\text { O projeto é demanda objetiva de gestão } \\
\text { do Comitê ou dos sub-comitês e está } \\
\text { explicitamente configurado nos } \\
\text { documentos analisados }\end{array}$ & Alto & 6 \\
\hline Interligados à gestão & $\begin{array}{l}\text { O projeto vai ao encontro das necessidades de } \\
\text { gestão do CBH - AT ou de seus sub-comitês, } \\
\text { porém, não são identificados claramente nos } \\
\text { documentos formais }\end{array}$ & Médio & 3 \\
\hline Independentes & $\begin{array}{c}\text { São aqueles projetos apresentados pelos } \\
\text { segmentos que não se configuram em } \\
\text { demandas objetivas de gestão definidas pelos } \\
\text { comitê e sub-comitês }\end{array}$ & Baixo & 0 \\
\hline Origem & Critérios & Escala & ação \\
\hline $\begin{array}{l}\text { Regional (Estado/ } \\
\text { Consórcios/parcerias } \\
\text { interinstitucionais) }\end{array}$ & $\begin{array}{c}\text { Projetos com origem no segmento } \\
\text { Estado/Consórcios intermunicipais ou } \\
\text { instâncias que atuam no âmbito regional ou } \\
\text { sub-regional - (maior responsabilidade } \\
\text { da gestão regional) }\end{array}$ & Alto & 6 \\
\hline $\begin{array}{l}\text { Municipal (Municípios } \\
\text { e parcerias entre } \\
\text { municípios e Sociedade } \\
\text { Civil) }\end{array}$ & $\begin{array}{l}\text { Projetos com origem no segmento município } \\
\text { ou que privilegiam as parcerias público-privada } \\
\text { (ações de alcance municipal) - responsabilidade } \\
\text { da gestão municipal/local }\end{array}$ & Médio & 3 \\
\hline $\begin{array}{c}\text { Localizada (Instâncias } \\
\text { localizadas ou Sociedade } \\
\text { Civil isolada) }\end{array}$ & $\begin{array}{l}\text { Projetos com origem em instâncias que atuam } \\
\text { de forma localizada - não } \\
\text { implicando em uma contribuição à articulação } \\
\text { entre os segmentos }\end{array}$ & Baixo & 0 \\
\hline
\end{tabular}

Tabela 5 - Escalas de avaliação conforme os níveis do indicador Valores Contratados

\begin{tabular}{|c|c|c|c|}
\hline Níveis & Critérios & \multicolumn{2}{|c|}{ Escala de articulação } \\
\hline Acima de $150.000,01$ & $\begin{array}{l}\text { Projetos que exigem valores "grandes" de } \\
\text { investimento }\end{array}$ & Alto & 6 \\
\hline $\begin{array}{c}\text { de } R \$ 70.000,01 \mathrm{a} \\
150.000,00\end{array}$ & $\begin{array}{l}\text { Projetos que exigem valores médios de } \\
\text { investimento }\end{array}$ & Médio Alto & 4 \\
\hline $\begin{array}{l}\text { de } R \$ 30.000,01 \mathrm{a} \\
\mathrm{R} \$ 70.000,00\end{array}$ & $\begin{array}{c}\text { Projetos que exigem baixos valores de } \\
\text { investimento }\end{array}$ & Médio Baixo & 2 \\
\hline Até R\$ 30.000,00 & $\begin{array}{l}\text { Projetos que exigem muito pouco } \\
\text { investimento }\end{array}$ & Baixo & 0 \\
\hline
\end{tabular}


indicador denominado "articulação". Ou seja, considera-se a computação de um único indicador formado a partir do conjunto de indicadores originais estabelecidos anteriormente. Por meio desse raciocínio, considerou-se que a articulação é mensurada segundo uma progressão de categorias, ou indicadores, na qual o primeiro nível corresponderia a categorias nominais (tipos de articulaçóes) e o segundo nível a categorias ordinais (níveis ou intensidades da articulação). Ou seja, admitindo-se a existência de um nível de mensuração superior ao original dos indicadores selecionados, tem-se uma nova variável - articulação - que assume múltiplos valores, uma vez que um projeto apresenta diferentes níveis de intensidade para cada indicador isolado.

Nesta estratégia, computa-se o fenômeno articulaçáo como a soma de presença de tipos diversos de articulação: um projeto com nível alto de articulação intersetorial, nível alto de abrangência, nível alto de gestão, nível alto de origem e nível alto de valor contratado é superior a um projeto que apresenta algum ou dois níveis inferiores em um dos indicadores selecionados e assim por diante. Sendo assim, realizou-se um procedimento de homogeneização ou normalização das escalas adotadas para cada indicador, uma vez que as escalas diferem entre si quanto aos níveis (para os indicadores "intersetorialidade" e "valores do contrato" têm-se quatro níveis de graduação da escala e, para os demais, somente três). Como conseqüência das atribuiçôes de notas aos distintos níveis das escalas adotadas, apresentadas nos quadros anteriores, tem-se que um determinado projeto analisado poderá ter um valor máximo de 30 unidades pela soma de "scores" de cada indicador avaliado separadamente, ou seja, pelo valor da nota final do projeto.

\section{Determinação da confiabilidade do conjunto de indicadores do fenômeno "articulação"}

Para mensurar a consistência ou confiabilidade do indicador síntese do fenômeno articulação dos projetos FEHIDRO, o método selecionado consistiu na aplicação da Análise de Con- fiabilidade (Pereira, 1999). Este método estatístico implica na elaboração das escalas mensurando a intensidade (notas) dos indicadores característicos do fenômeno articulação em separado e sua contribuição para uma escala que seja o somatório das notas isoladas de cada indicador. A soma resultante deverá corresponder à intensidade atribuída ao fenômeno, de modo que a parcela verdadeira seja significativamente maior que a parcela aleatória de erro.

Assim sendo, adota-se o modelo clássico de teste da contribuição de uma medida de resposta (nota atribuída a um determinado indicador) para representação do conceito objetivado. Este modelo é definido como se segue: $\mathrm{X}_{\mathrm{i}}=\operatorname{tau}_{\mathrm{i}}+$ erro $_{\mathrm{i}}$.

Nesta equação "X" refere-se à nota atribuída ao indicador individual "i", de acordo com os critérios definidos para avaliação; "tau" refere-se à sua nota verdadeira e "erro" à parcela aleatória componente da medida, que representa o desvio entre a contribuição real do indicador e a medida realizada. A nota final atribuída ao fenômeno será então definida pela soma da nota atribuída a cada indicador da escala.

Também foi determinado que o conjunto dos indicadores tivesse contribuiçãao homogênea na explicação do fenômeno, de forma que as notas dadas refletissem pesos iguais na explicação do fenômeno.

A determinação da confiabilidade da escala adotada segue a seguinte concepção:

- Tendo vários projetos em avaliação e conseqüente atribuiçãao de notas distintas, pode-se calcular, em separado, a variância para cada indicador e a variância para nota final.

- Se os valores atribuídos a cada indicador dos projetos verdadeiramente medem o fenômeno, então a variância da nota final dos projetos será menor que a soma das variâncias de cada indicador.

- Portanto, pode-se estimar a proporção de variação verdadeira capturada pelo processo de atribuição de notas, comparando variância da nota final dos projetos e a soma das variâncias de cada indicador.

Especificamente, então se calcula:

Alfa de Cronbach $=[\mathrm{k} /(\mathrm{k}-1)]^{*}$ * [1-[Somatório $\left.\left.\left(\mathrm{s}_{\mathrm{i}}^{2}\right)\right] / \mathrm{s}_{\mathrm{nf}}{ }^{2}\right]$
Em que:

$\mathrm{k}=$ número total de indicadores avaliados;

$\mathrm{s}_{\mathrm{i}}^{2}=$ variância de cada indicador;

$\mathrm{s}_{\mathrm{nf}}{ }^{2}=$ variância da nota final.

O coeficiente "Alfa de Cronbach" assume valores entre 0 e 1 , sendo que um valor igual a 1 significa que todos indicadores analisados medem o mesmo fenômeno, sendo perfeitamente confiáveis.

\section{ESTUDO DE CASO: AVALIACÃO DAS AÇOES D̉O COMITÊ DO ALTO TIETÉ}

Antes da apresentação dos resultados é fundamental explicitar a organização do Comitê do Alto Tietê bem como a natureza do objeto que foi avaliado.

\section{Caracterização das ações do Comitê da Bacia do Alto Tietê}

O Comitê da Bacia Hidrográfica do Alto Tietê (CBH - AT) é a instância responsável pelas deliberações de assuntos relacionados aos recursos hídricos na Bacia Hidrográfica do Alto Tietê (região que quase se confunde com a RMSP). Devido às dimensões dessa bacia e complexidade de seus conflitos, esse comitê é subdivido em cinco instâncias descentralizadas, os sub-comitês, equiparados às suas cinco sub-bacias principais: Cotia - Guarapiranga; Billings - Tamanduateí; Tietê - Cabeceiras; Juqueri - Cantareira e Pinheiros - Pirapora.

O CBH - AT é composto por 16 representantes e respectivos suplentes de cada segmento - Estado, Município e Sociedade Civil, eleitos a cada dois anos. A estrutura organizacional dos sub-comitês é semelhante à do comitê central diferindo em relação ao número de representantes e rotatividade da representatividade dos municípios. O município de São Paulo tem assento garantido tanto no $\mathrm{CBH}$-AT quanto nos sub-comitês em função do seu papel central na dinâmica econômica, populacional e política da Bacia do Alto Tietê.

As açôes do Comitê da Bacia do Alto Tietê e seus sub-comitês ${ }^{3}$ expressam-se, em suas deliberações e nos proje-

${ }^{3}$ Em Alvim (2003) encontra-se a análise detalhada das açōes do Comitê da Bacia do Alto Tietê e de seus sub-comitês realizadas para o período definido a partir da leitura e sistematização de todas as atas, dos documentos disponibilizados por essas instâncias e entrevistas com atores representativos dos três segmentos. 
tos aprovados anualmente, que recebem recursos advindos do FEHIDRO. Cada assunto é tratado nas plenárias dessas instâncias e passa por um processo democrático de discussão e votação.

As deliberaçôes, em geral, são assuntos encaminhados e votados de forma paritária pelas instâncias, que concretizam, principalmente, as atribuiçóes dos organismos de gestão das águas e quando são votados no âmbito dos sub-comitês devem ser referendados pelo Comitê da Bacia. Como este tem uma natureza deliberativa e não executiva, em geral, sua atuação limita-se a recomendações referentes a Planos, Estudos, Legislaçóes, entre outros, que dependem, na maioria das vezes, do Estado ou dos municípios para sua execução.

Já os projetos aprovados nas plenárias do Comitê da Bacia e dos sub-comitês podem ser caracterizados como as ações mais efetivas, uma vez que, recebem recursos financeiros do FEHIDRO para tal. Cabe destacar que, embora esses recursos, na ocasião da pesquisa, fossem pouco expressivos, em função da não aprovação da cobrança da água, sempre foram bastante disputados por todos os segmentos tanto no Comitê da Bacia quanto nos sub-comitês.

Em relação ao universo pesquisado, de acordo com levantamento realizado na Secretaria Executiva do Comitê da Bacia do Alto Tietê, de 1996 a 2002 foram aprovados 164 projetos, envolvendo interesses do Comitê da Bacia e de seus sub-comitês. Desse universo, 57 projetos foram apresentados por tomadores do segmento Sociedade Civil, 57 do Estado e 50 do Município, ou seja, ocorreu quase que um equilíbrio entre o número de projetos aprovados por cada segmento.

Dos 164 projetos aprovados, somente 77 (47\%) foram realmente contratados até meados de 2002, dos quais, 40 (52\%) foram concluídos e 37 (48\%) estavam em andamento. Os demais, 87 projetos (43\%), estavam em tramitação nos respectivos organismos de aprovação (Secretaria Executiva do Comitê da Bacia, no Agente Técnico ou no Agente Financeiro do COFEHIDRO). Em geral, entrevistas com técnicos do SIGRH apontaram como principais problemas em relação à morosidade da contratação dos projetos os seguintes aspectos: a excessiva demora dos tomadores em regulamentarem a documentação exigida pelo COFEHIDRO, a lentidão na aprovação dos projetos em função das várias instâncias por que passam aliada ao número reduzido de agentes técnicos e a demora no nível de desembolso dos recursos pelo agente financeiro.

Em relação às áreas de interesse dos projetos, $26 \%$ foram destinados à sub-região Cotia-Guarapiranga; 18\% à sub-região Tietê-Cabeceiras; $16 \%$ à Bacia (Geral); 15\% à sub-região Billings-Tamanduateí; 13\% à JuqueriCantareira; e 12\% à sub-região Pinheiros- Pirapora.

Antes de sua avaliação os projetos foram classificados pela pesquisa, segundo a natureza do assunto, como forma de entender as ações priorizadas pelo Comitê da Bacia. Tal avaliação partiu da analise de cada processo arquivado na Secretaria Executiva do COFEHIDRO e foram complementados com entrevistas realizadas no âmbito do Comitê da Bacia e dos sub-comitês. Dos 164 projetos aprovados, a pesquisa permitiu classificar um total de 146 projetos em função da descrição apontada nos documentos pesquisados (as informações dos demais eram imprecisas).

A Figura 1 apresenta a distribuição dos projetos em porcentagem, segundo a natureza do assunto. Nota-se que os projetos que envolvem educação ambiental e planos/projetos/estudos destacam-se do conjunto da amostra, com $45 \%$ e $30 \%$, respectivamente. Os projetos aprovados que envolvem obras ocupam 13\% do conjunto, $4 \%$ são aqueles ligados à gestão e $7 \%$ tratam de outros assuntos (reflorestamento, fiscalização etc.).

A seguir, os principais resultados provenientes da aplicação da metodologia no estudo de caso escolhido são apresentados.

\section{Aplicação da metodologia}

Do universo de 164 projetos deliberados pelo CBH-AT, no período de 1996 a 2002, considerou-se então a amostra de 146 para aplicação da metodologia, cujas informações estavam completas para viabilização da análise. Para o universo selecionado elaborou-se uma matriz atribuindo a cada projeto a avaliação segundo os níveis de articulação identificados nos indicadores selecionados: Intersetorialidade, Abrangência territorial, Gestão, Origem do Projeto e Valor Contratado.

As Figuras 2 e 3, resumem as avaliaçóes realizadas reunindo as freqüências dos resultados obtidos no âmbito de cada indicador nos 146 projetos selecionados, com o intuito de prover uma síntese.

Observa-se que, em relação aos dois primeiros indicadores apresentados na Figura 2, se sobressaem as escalas média baixa para o indicador intersetorialidade e média alta para $o$ indicador valor contratado. No segundo conjunto de indicadores, a situação difere. Nota-se que a escala que se destaca para o indicador abrangência territorial é o nível alto de articulação, enquanto para o indicador gestão, o nível baixo sobressai-se em relação aos demais. $\mathrm{O}$ último indicador, origem do projeto, apresenta um equilíbrio em relação aos três níveis.

Em síntese, os projetos aprovados pelo Comitê do Alto Tietê vêm se mostrando articulados em relação à escala territorial, uma vez que a maioria indica benefícios à bacia ou às subbacias. Em seguida, com intensidade

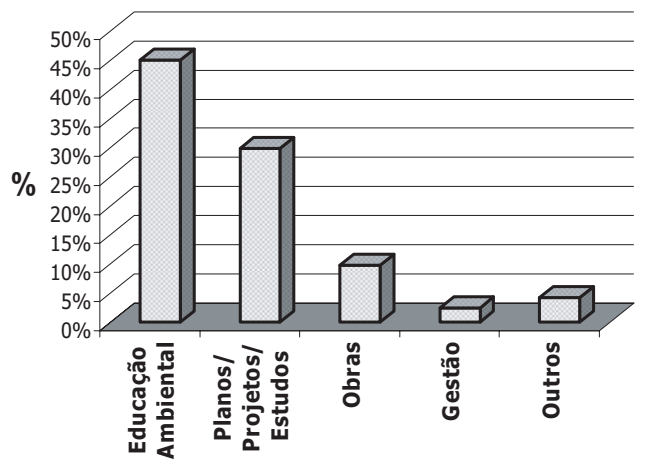

Fonte: $\mathrm{CBH}$ - AT. Secretaria Executiva. Gráfico elaborado segundo critérios adotados por Alvim, A.T.B., 2003

Figura I- Projetos aprovados segundo a natureza do assunto - 1996 /2002 (\%) 
média-alta estão os projetos com valores contratados entre R $\$ 70.000,00 \mathrm{e}$ $\mathrm{R} \$ 150.000,00$. Em relação ao indicador Intersetorialidade o resultado da avaliação foi considerado abaixo da média, em função de uma pequena parcela de projetos que apresentam articulação com os setores do grupo indireto. A articulação é ainda mais baixa em relação ao indicador gestão, significando que o Comitê da Bacia tem aprovado poucos projetos de interesse para a gestão da bacia e sub-bacias, expressos em seus documentos formais. Já em relação à origem do projeto ou origem da demanda, observa-se que os agentes responsáveis pela gestão da bacia ou das sub-bacias contribuem em relação a $1 / 3$ dos projetos, evidenciando uma distribuição equilibrada em relação aos três segmentos, não predominando nenhum nível.

\section{Análise de confiabilidade para o indicador "articulação"}

Para verificação da confiabilidade dos indicadores que compóem o fenômeno articulação dos projetos avaliados, as escalas foram normalizadas de forma a refletir o mesmo peso. Como conseqüência das atribuiçôes de notas e pesos adotados, observa-se que um projeto pode variar de 0 a 30 , de acordo com a soma de "scores" de cada indicador avaliado separadamente.

$\mathrm{O}$ método de análise da confiabilidade dos indicadores selecionados para mensurar o fenômeno articulação (síntese dos indicadores selecionados) foi aplicado por meio do software STATISTICA referido ao respectivo manual (STATISTICA for Windows, 1995) e de acordo com a metodologia abordada em Pereira (1999).

Os resultados gerais alcançados estão sintetizados na Tabela 6 .

\section{DISCUSSÃO DOS RESULTADOS}

De acordo com os dados expostos no sumário da escala adotada, a média da escala para o indicador síntese construído foi de 13,8 pontos para a amostra de projetos válidos. Considerando a escala entre 0 e 30 pontos, o resultado aponta para uma concentração de notas finais um pouco abaixo da média da escala total, situada em 15 pontos. O indicador gestão apresentou-se mais próximo da média.

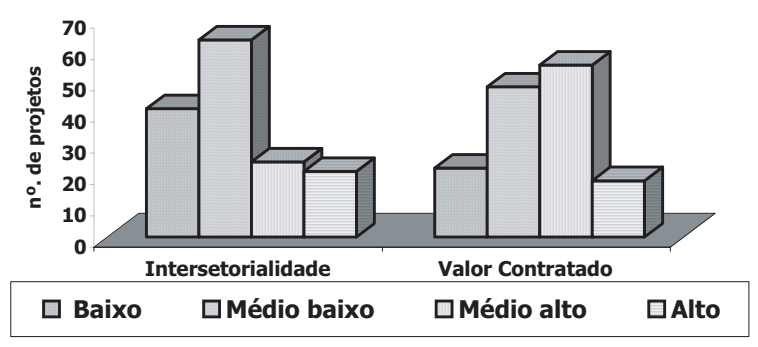

Figura 2 - Freqüências dos resultados dos níveis de articulação dos indicadores "intersetorialidade" e "valor contratado"

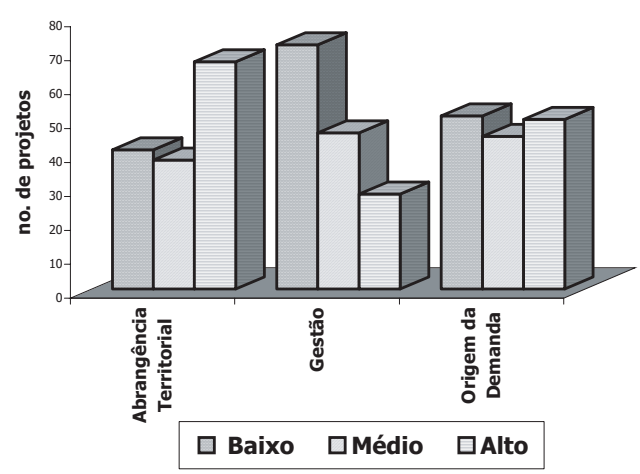

Figura 3 - Freqüências dos resultados dos níveis articulação dos indicadores "abrangência territorial", "gestão" e "origem da demanda"

O desvio padrão resultante foi 8,09 , ou seja, cerca de $66 \%$ dos projetos concentram-se 8 pontos acima ou abaixo da média encontrada. Situando dentro da escala, pode se admitir que os resultados para uma amostra maior serão distribuídos normalmente. Os indicadores que contribuem para uma maior concentração junto à média são "Intersetorialidade" e "Valores".

Pelo coeficiente Alfa de Cronbach, que trabalha a relação entre covariâncias e variâncias internas das medidas, observa-se que $76,8 \%$ do fenômeno articulação pode ser explicado pelo conjunto de indicadores analisados. De acordo com Pereira (1999), este valor para Alfa representa considerável explicação para o fenômeno, ou seja, uma confiabilidade "boa" apesar de não perfeita do sistema de notas adotado (quanto mais próximo de 1 melhor).

O índice Correlação Inter Indicadores mostrou-se baixo, com média de $40 \%$, evidenciando que os indicadores escolhidos são independentes entre si, o que é desejável neste tipo de análise.

Em síntese, o conjunto de indicadores se mostrou internamente consistente, pois todos apresentaram individualmente alguma correlação com o fenômeno a ser mensurado entre $45 \%$ e $65 \%$. Por outro lado, todos acrescentaram sua parcela de explicação para o fenômeno, com destaque para o indicador "Gestão".

O resultado final da avaliação dos projetos quanto ao indicador articulação, segundo a escala de pontos obtida a partir da normalização, é apresentado de forma sintetizada na Tabela 7 , de acordo com o número de projetos e com quatros faixas possíveis na escala adotada, distribuídas uniformemente. Observa-se que dos 146 projetos avaliados, 52 projetos estão acima da média de 15 pontos - nas faixas $3 \mathrm{e}$ 4. Esse resultado indica que $36 \%$ dos projetos aprovados pelo Comitê da Bacia do Alto Tietê podem contribuir à gestão integrada da bacia hidrográfica metropolitana de São Paulo.

Analisando em separado os projetos classificados acima da média, nota-se que 25 encontram-se na faixa 4 (superior) e são considerados, por esta avaliação, como aqueles que se mostram mais articulados à gestão da bacia. Deste universo, 21 projetos são classificados, segundo a natureza do 
Tabela 6 - Análise individual da contribuição dos indicadores

\begin{tabular}{cccccc}
\hline Indicadores & $\begin{array}{c}\text { Escala média } \\
\text { se excluído }\end{array}$ & $\begin{array}{c}\text { Escala da } \\
\text { variância } \\
\text { se excluído }\end{array}$ & $\begin{array}{c}\text { Desvio } \\
\text { padrão se } \\
\text { excluído }\end{array}$ & $\begin{array}{c}\text { Correlação } \\
\text { total do } \\
\text { item }\end{array}$ & $\begin{array}{c}\text { Alfa de } \\
\text { Cronbach } \\
\text { se excluído }\end{array}$ \\
\hline Intersetorialidade & 11,56081 & 49,16522 & 7,011792 & 0,452095 & 0,753723 \\
Valor do Projeto & 10,76351 & 49,28867 & 7,020589 & 0,486705 & 0,744885 \\
Gestão & 11,72297 & 40,51109 & 6,364832 & 0,654017 & 0,683529 \\
Abrangência territorial & 10,30405 & 39,73863 & 6,303858 & 0,589518 & 0,708452 \\
Segmento de demanda & 10,81081 & 41,58583 & 6,448708 & 0,533565 & 0,730135 \\
\hline
\end{tabular}

Sumário para a Escala: Média = 13,7905; Desvio padrão = 8,09405; Número de casos válidos = 146; Alfa de Cronbach: 0,768286; Correlação Inter-Indicadores: 0,405270

Tabela 7 - Síntese da avaliação final do Indicador Articulação dos Projetos FEHIDRO no Comitê do Alto Tietê

\begin{tabular}{ccc}
\hline Faixas na escala & Pontos na escala & Número de projetos \\
\hline Faixa 1 & 0 a 7 & 35 \\
Faixa 2 & 8 a 15 & 59 \\
Faixa 3 & 16 a 22 & 27 \\
Faixa 4 & 23 a 30 & 25 \\
Total de projetos válidos & 146 \\
\hline
\end{tabular}

assunto, em Planos/Projetos/Estudos, e quatro relacionam-se à Educação Ambiental. Destaca-se que os projetos que obtiveram maior avaliação referemse aos instrumentos de diagnóstico e planejamento da bacia e das sub-bacias (planos regional e sub-regionais, leis específicas, diagnósticos sócio-ambientais, bases cartográficas etc.) ou são aqueles voltados para açóes amplas de educação ambiental que se aliam à capacitação de recursos humanos. Tais projetos são conjuntamente importantes à gestão das águas e do território e podem contribuir, se implantados, a uma melhoria das condiçóes físicas e ambientais da bacia.

É importante ressaltar que, a maioria dos projetos que obteve nível mais alto de articulação foi aprovada somente a partir de 1999. Isso significa que o Comitê da Bacia do Alto Tietê e seus sub-comitês modificaram, ao longo dos três últimos anos da pesquisa, o desempenho quanto à contratação de projetos necessários ao efetivo gerenciamento dos recursos hídricos, beneficiando, conseqüentemente, a gestão integrada da Bacia do Alto Tietê.

\section{CONCLUSÃO}

A metodologia descrita se mostrou extremamente útil na avaliação dos pro- jetos aprovados pelo Comitê da Bacia do Alto Tietê e seus sub-comitês. Ela permitiu demonstrar que a articulação de suas ações em relação à alocação de verbas se mostra ainda abaixo da média uma vez que grande parte da amostra selecionada não expressa o fenômeno articulação por meio dos indicadores selecionados. Os principais fatores identificados como relevantes a pouca articulação das ações do Comitê são os seguintes: limitações financeiras desses organismos; a ausência inicial de critérios claros, em relação à distribuição dos recursos financeiros (em especial entre 1995 e 1998); a pulverização dos recursos financeiros em diversos projetos na tentativa de beneficiar todos os segmentos, principalmente, nos três primeiros anos de vigência do Comitê da Bacia.

Contudo, evidencia-se, principalmente a partir de 1999, que existe uma crescente disposição dessas instâncias em aplicar seus recursos de forma a programar ações que venham contribuir à gestão integrada da bacia metropolitana. Os seguintes assuntos discutidos e aprovados em plenárias se mostram relevantes ao equacionamento dos conflitos entre os recursos hídricos, o meio ambiente e o uso e ocupação do solo da bacia, indicando uma plena disposição em articular a gestão da água às políticas setoriais e municipais da metrópole, em diversos níveis: instrumentos de planejamento e gestão da bacia - o Relatório "Zero" e o Plano de Bacia -; diagnósticos sócio-ambientais e mapeamento da bacia e sub-bacias; e ações direcionadas à regulamentação da nova Lei Estadual de Proteção e Recuperação dos Mananciais, Lei Estadual no. 9.866/1997. (Silva \& Porto, 2003; Alvim, 2003)

Como observação final, destacase que essa metodologia foi utilizada por José Flávio Cury em 2006 em sua tese de doutorado na FAU/USP (Cury, 2006). Por meio dela, esse autor demonstrou que as ações do Comitê da Bacia Hidrográfica do Alto Paranapanema, no Estado de São Paulo, entre 1996 e 2004 contribuíram para a gestão integrada dessa bacia. Dos 90 projetos do Comitê da Bacia avaliados, 46 estão acima da média real obtida pelos projetos de 23,73 pontos, o que representa $51 \%$ da amostra selecionada e 80 deles (88\%) estão acima da média de corte aceitável de 20 pontos (Cury, 2006). Em outras palavras, a metodologia utilizada permitiu concluir nesse caso que grande parte da amostra expressa o fenômeno da articulação por meio dos indicadores selecionados e pode ser aplicada a outras realidades.

Ao defender os princípios da teoria da gestão integrada de uma bacia, 
demonstra-se, por meio desta avaliação, que a gestão das águas deve buscar uma ampla articulação entre as diversas políticas setoriais e as distintas instâncias que atuam na bacia e constantemente conflitam. Entretanto, assinalase que apenas a atuação de um comitê de gestão das águas não é suficiente para atingir a gestão integrada da bacia hidrográfica, entendida aqui como um território complexo repleto de conflitos de diversas ordens.

No caso do Comitê da Bacia Hidrográfica do Alto Tietê, embora a pesquisa tenha identificado um esforço relevante desse fórum em agregar setores, instâncias e atores com a finalidade de equacionar os conflitos relacionados aos recursos hídricos, sabese que as soluções não necessariamente dependem somente de suas ações. Ressente-se, nesse caso, a ausência de um organismo de gestão metropolitana que exerça as funções públicas previstas na Constituição Estadual de 1989 e na Lei Estadual Complementar n'. 760/94 de gerir os interesses comuns entre os municípios e os conflitos inter-setoriais presentes, principalmente, nos organismos estaduais. Ressalta-se que essa questão permanece em aberto na maior metrópole do País.

Ou seja, apenas o gerenciamento dos recursos hídricos não é suficien-te para efetivar a gestão integrada da bacia. O desafio que se coloca é a implementação de um sistema de gestão metropolitano que viabilize um processo de planejamento integrado articulando de forma compartilhada os municípios, a sociedade local, bem como os Comitês da Bacia em torno de objetivos comuns para o alcance de soluções em relação aos conflitos, principalmente aqueles relativos aos usos da água e do território.

\section{REFERÊNCIAS}

ALVIM, A. T. B. A Contribuição do Comitê do Alto Tietề à Gestão da Bacia Metropolitana. Tese (Doutorado em Arquitetura e Urbanismo) - Faculdade de Arquitetura e Urbanismo, Universidade de São Paulo, São Paulo. 549f. 1994 - 2001. 2003.

CURY, J. F. A gestão integrada de bacias hidrográficas: a abertura de uma oportunidade para o desenvolvimento sustentável do Alto Paranapanema. Tese (Doutorado em Arquitetura e Urbanismo) - Faculdade de Arquitetura e Urbanismo, Universidade de São Paulo, São Paulo. 350f. (1994-2004). 2006

DOUROJEANNY, A. Las Cuencas Hidrográfcas: Una Opción Territorial para Dirigir Acciones Tiendentes la Sustentabilidad Ambiental. In: TERCERA CONVENCIÓN NACIONAL DE REGANTES Y USUARIOS DEL AGUA, CONFERENCIA DE CANALISTAS DEL CHILE., Los Angeles. Anais... .Los Angeles, Chile: CEPAL, 1993 (tradução nossa).

FRACALANZA, A. P. Conflitos na Apropriação da Água na Região Metropolitana de São Paulo. Tese (Doutorado em Geografia). Curso de Geografia, Faculdade de Ciências e Tecnologia, UNESP, Presidente Prudente. 320f. 2002.

MUNÕZ, H. R. Razões para um debate sobre as interfaces da Gestão dos recursos hidricos no contexto da lei de Águas de 1997. In: MUNŌZ, H. R. (org.). Interfaces da Gestão de Recursos Hídricos. Desafios da lei de águas em 1997. Brasília 2. ed. Brasília: Secretaria de Recursos Hídricos, 2000. Disponível no site: $<$ http//www.mma.gov. br>. Acessado em 7 abr. 2002.
PEREIRA, J. C. R. Análise de dados qualitativos. Estratégias Metodológicas para as Ciências da Saúde, Humanas e Sociais. 1. ed. São Paulo: EDUSP / FAPESP, 160p, 1999.

SACHS, I. Estratégias de Transição para o Século XXI. Desenvolvimento e Meio Ambiente. São Paulo: Studio Nobel - Fundap, 104 p., 1993

SILVA, R. T. Gestão Integrada de Bacias Hidrográficas densamente urbanizadas. In: FONSECA, R. B. (org.), Livro Verde: desafios para a gestáo da Região Metropolitana de Campinas. Campinas: Unicamp. IE, p.451-484, 2000.

SILVA, R. T.; PORTO, M. F. A. Gestão urbana e gestão das águas: caminhos de integração. Estudos Avançados, v. 17 , n. 47 , p. 129 - 145, Jan/ Abr, 2003.

STATISTICA FOR WINDOWS 95, (v. III). Statistics II, 2nd, Copyright 1984-1994 StatSoft Inc., Tulsa OK USA, 1995. Conjunto de programas. CD-ROM.

Endereço para correspondência:

Angélica A. Tanus Benatti Alvim Universidade Presbiteriana Mackenzie

Faculdade de Arquitetura e Urbanismo Rua da Consolação, 930, Prédio 9 Consolação

01302-907 - São Paulo, SP - Brasil Tel.: (I I) 2 I I4-83 I3

Email: abalvim@mackenzie.com.br 